\title{
Tunisian consumers perception and behavior towards organic food products
}

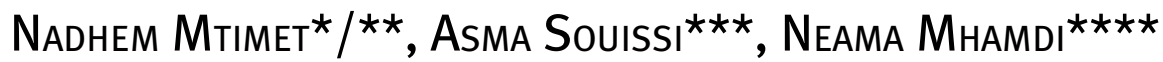

DOI: $10.30682 / \mathrm{nm} 2001 \mathrm{a}$

JEL codes: M31, Q11, Q19

\begin{abstract}
Organic agriculture production in Tunisia is relatively recent and was mainly oriented to the export market. However, local market demand is growing for such products. The objective of the current study is to assess consumers' awareness and consumption of organic food products. A survey was implemented and included 250 respondents from the capital city Tunis. We used descriptive statistics, factor and cluster analysis to analyze the data. The results indicated that respondents' perceptions towards organic food are positive. Four groups of consumers were identified with respondents from the main three groups have good understanding about organic food products characteristics. However, the proportion of consumers who purchase organic food on a regular basis is quite low (16\%). Improving availability and access to organic products through the integration in mainstream sales channels and lower price premiums will help narrowing the gap between the intention to purchase organic products and the actual purchase.
\end{abstract}

Keywords: Demand, factor and cluster analysis, organic food, Tunisia.

\section{Introduction}

From the last decades, consumers are paying more attention to the food they eat. Not only they are interested in a diverse variety of foods with better taste and nutrition quality, but they are also increasingly concerned with issues related to food safety, human health, animal welfare (Harper and Makatouni, 2002), conventional agricultural practices and environmental sustainability (Wandel and Bugge, 1997). In fact, over the years, consumers have realized that their purchasing and consumption behaviors have a direct impact on many ecological and environmental problems (Laroche et al., 1996).
As a result of this change in consumer's attitudes and behavior, interest in organically produced food is increasing throughout the world. The organic agriculture and product market expanded at a remarkable rate. (Bhaskaran et al., 2006; Sahota, 2014; Popa et al., 2019). Organic agricultural land has increased six-fold since 1999 (Willer and Lernoud, 2019).

Today more than 179 countries are practicing organic farming. The number of farms and agriculture land are increasing every day. 50.9 million hectares are organically grown which represents only $1.1 \%$ of total agricultural land worldwide. Currently, the countries with the largest organic areas are Australia (35.6 million

\footnotetext{
* International Livestock Research Institute (ILRI), Nairobi, Kenya.

** University of Carthage, Higher School of Agriculture, Mograne, Zaghouan, Tunisia.

*** University of Sousse, Higher Agronomic Institute of Chott Meriem, Sousse, Tunisia.

**** Ste Ghraieb de Nutrition, M'saken, Tunisia.

Corresponding author: n.mtimet@cgiar.org
} 
hectares), Argentina (3.3 million hectares), and China ( 3 million hectares). In Europe, 14.6 million hectares of agricultural land were managed organically by almost 456,000 producers. Organic farmland has increased by approximately 102\% since 2007 (Willer and Kilcher, 2009; Willer and Lernoud, 2019).

Global demand for organic products is increasing; sales are rising on average by 4.2 billion US dollars every year. Estimations indicate that sales have reached 97 billion US dollars in 2017. Consumer demand for organic products is concentrated in North America (approximately $47 \%$ of the global market) and Europe (35\%) (Willer and Lernoud, 2019).

Policies for organic agriculture have been set up, defining organic production, processing and marketing through agro-environment measures (Tuson and Lampkin, 2004). New regulations on organic production - EU Regulation (EC) $834 / 2007$ - and its implementation rules came into force on January 2009. A proposal to amend this regulation was published by the European Commission in 2014. Farmers in Europe, as well as those from importing countries, have to deal with the new regulation and rules. In 2018, 93 countries have implemented regulations on organic farming, and 16 countries are in the process of drafting a regulation. There are 576 organizations worldwide offering organic certification services. Most certification bodies are located in the European Union (EU), USA, Japan, South Korea, China, Canada, and Brazil (Willer and Kilcher, 2010; Willer and Lernoud, 2019).

The growth of organic agriculture practices is not only due to improving food security, rural development, sustainable livelihoods and environmental integrity, but it is also seen as part of the emerging marketing trends where consumers pay more attention to the health benefits a food could deliver before making a purchasing decision. Although there is an increasing awareness about organic products, many studies showed that, until now, consumers are not consistent in their interpretation of what is organic (Hutchins and Greenhalgh, 1995; Bonti-Ankomah and Yiridoe, 2006; Callieris et al., 2016).

In relation to the growing potential of consumer demand and its limitations, researchers have identified and ranked motivations for buying organic products and results showed that people who purchase organic food could be classified into five groups namely: "greens": persons who are concerned about the environment; "food phobic": those who are concerned about chemical residues in food; "healthy eaters": consumers who, for various (medical or other) reasons, follow particular diet sets; "humanists": people who are preoccupied with farming methods; and "hedonists": persons who believe that premium products must be better and importantly taste better (Davies et al., 1995). A more recent classification is reported by Nasir and Karakaya (2014). In their study, the authors indicate that organic products consumers could be segmented into three groups. Based on the behavioral beliefs, they distinguish between consumers who have "favorable", "neutral" and "unfavorable" attitudes toward organic foods. Peštek et al. (2018), attempted to identify and characterize segments of organic food buyers in a newly developing market within the southeastern European region. Four distinct segments of organic food buyers were identified. Those segments were named as enthusiastic social-seekers, enthusiastic moralists, hostile seldom shoppers, and hostile heavy shoppers. Such considerations could come only from well-informed citizens who are aware of, and fully committed to their rights to quality health and environment. Thus, the need to assess consumer's awareness, knowledge and attitude to potentially boost the demand for organic products and change consumers' behavior.

Since demand of any product is driven by convenience and habit, which is difficult to change, the study of consumers' perceptions and preferences is of high importance for marketing strategy and decision makers. Besides, organic products are credence goods, consumers (unlike producers who are aware that their products are organic) may not know whether a product is produced using organic or conventional methods, not even after repeated purchase and consumption, unless they are told so (Giannakas, 2002). Thus, awareness and knowledge about organically produced foods play a critical role in consumer purchase decision. If an individual cannot clearly differentiate between two alter- 
native products, a price premium on the organic product can confuse and/or affect the individual's purchasing decision, in favor of the cheaper product.

In Tunisia organic production was initially and essentially intended to the export market. Nevertheless, nowadays, changes in lifestyle, per-capita income increase for a segment of population, openness to other cultures, increasing awareness of consumers about health and environmental issues, and the improvement of educational level have led to some changes in consumption patterns and have created a new demand for organic products in the local market.

There are many studies focusing on consumers' attitudes towards organic food/products. So far, there is little empirical data on organic products consumers' behavior in Tunisia. Most of existing studies took in consideration purchase and consumptions motivations of specific organic products such as olive oil (Dekhili et al., 2011), prickly pear seed oil (Ghali and Hamdi, 2015) and organic milk (Salah et al., 2015). Few studies studied the effect of perceptions and motivations on the purchasing behavior of consumers who intend to buy an organic product (Bahri-Ammari et al., 2015). In their study, Callieris et al. (2016) identified two groups of consumers who are aware of the benefits derived from the consumption of organic products and who are able to contribute to the expansion of the organic market.

Several attempts to segment Tunisian consumers of organic products have been made in recent years with the aim to develop the national organic market. However, food organic consumption in Tunisia has not grown as expected. Researchers provide essentially two main reasons: the lack of consumers' interest and the high prices of organic products (Salah et al., 2015; Callieris et al., 2016; Ghali-Zinoubi and Toukabri, 2019). In fact, there is low awareness of consumers about health and environmental issues related to food consumption that represent the most important motivation for organic food consumers according to many researches (Botonaki et al., 2006; Haghiri et al., 2009; Coulibaly et al., 2011). Socio-economic constraints and the high costs of production and certification which increase or- ganic food prices, negatively affect its demand by middle and low income consumer segments (Hamzaoui-Essoussi and Zahaf, 2008; Salah et al., 2015; Ghali-Zinoubi and Toukabri, 2019).

The previous studies assessing Tunisian organic products consumer behavior have either focused on a specific product (Dekhili et al., 2011 - olive oil; Ghali and Hamdi, 2015 - prickly pear seed oil; Salah et al., 2015 - milk; Ghali-Zinoubi and Toukabri, 2019 - olive oil); or have only focused on organic products consumers/buyers (Hamzaoui and Zahaf, 2008; Callieris et al., 2016) without including the non-buyers/ non-consumers. The current study tries to fill this gap and focus on both buyers/consumers and non-buyers/non-consumers of organic products in Tunisia with the aim to understand the factors influencing or hampering organic products consumption.

Therefore, in the present study we try to group consumers according to their perceptions of organic products to provide deeper insights into Tunisian consumer behavior towards organic products in order to identify suitable strategies to better position organic products in the local market and to promote this sector.

The paper is organized as follows: in the next section, we provide a succinct description of the organic agriculture in Tunisia. The third section describes the research methods and analytical approach, followed by the results and then the discussion sections. In the conclusions section we provide recommendations for the development of the local organic food market.

\section{Organic agriculture in Tunisia}

As previously indicated, in Tunisia organic agriculture is relatively recent and was mainly oriented to the export market. Local producers were motivated by the high prices and premiums European consumers were willingness to pay for organic products especially in the case of olive oil and dates (CTAB, 2009).

Tunisian organic production started during the eighties of the past century through private initiatives and experienced a slow development until the years 1997-1998. In 2010 a national strategy to boost the organic sector was developed. The 
strategy included several components: regulation, research, training, farm extension, organization, and support. The law No. 30 of 5 April 1999 marked the official birth of organic agriculture in Tunisia, the first country to implement a national organic regulation (Willer and Lernoud, 2019). The reference legislation is the IFOAM Basic Guidelines, EEC and the Tunisian regulations (Ben Kheder, 2002).

To guarantee the access to the European market, the certification of organic production was compulsory. Control and certification of organic products are provided, in Tunisia, by private organizations (like ECOCERT, IMC, LACON, INNORPI, etc.) approved by the Ministry of Agriculture, Hydraulic Resources and Fisheries.

Thanks to these measures and regulations, the sector of organic agriculture recorded a considerable increase both in production and in farmed area. The share of organic land reached around $3 \%$ of total agricultural land (Willer and Lernoud, 2019). The areas under organic agriculture reached 370,000 hectares in 2017 compared with 18,600 hectares in 2002 and 300 hectares in 1997 (CTAB, 2019). The number of operators (all value chain actors involved from production to commercialization) increased from 481 in 2002 to 4700 in 2017 (Figure 1). There has been a reduction in the area allocated to organic production during the period 2011-2016 which is mainly due to the instable social situation and climate after the Tunisian revolution and the constraints for the private certification companies to work. Since the year 2017, there was a steady increase of the total production area almost back to the same values before 2011 .

The financial incentives including subsidies may provide motivation for the adoption of organic farming. However, the most important factors are ethical values and farm structure $(\mathrm{Pa}-$ padopoulos et al., 2018).

Most of organic farms and processing units are located in the Centre, in the South and few in the North of the country. The main organic products in Tunisia are olive oil, palm date, wine, fruits, vegetables, aromatic and medicinal plants, and honey. There are mixed opinions about the fact that organic agricultural production in Tunisia has not reached its highest potential. In fact, for the organic olive oil production, as it is the case for the conventional olive oil production, the productivity is low compared to other countries like Italy and Spain. This is mainly due to the extensive production system depending on rainfalls and the type of olive varieties grown. In addition, labor-intensive harvesting increases the production costs in comparison to the mechanical one. In the case of dates, a study done by Rached et al. (2012) showed that organic farms have on average higher technical efficiency $(93 \%)$ compared to the conventional farms $(80 \%)$. Salah et al. (2016) found that the production costs of organic milk are higher compared to conventional milk, and its selling price exceeds $53 \%$ the price of conventional milk while consumers are willing to pay only $25 \%$ premium for a milk without chemical residues.

Today Tunisia is the second largest exporter of organic products in Africa (mainly olive oil, dates, vegetables, aromatic and medicinal plants and vines). It is supported by a network of certification and control structures (ITES, 2017). In 2018 , the exported quantities of organic products were estimated at 48,500 tons for a value of 504 million Tunisian dinars (around US dollars 186 million). These exports included 60 products and 36 destination countries (CTAB, 2019). As olive growing accounts for nearly $90 \%$ of organic agricultural land in Tunisia, olive oil represents the most exported organic agri-food product $(38,000$ tons in 2018$)$ with only $22 \%$ of the volumes exported as packaged. Price of organic olive oil was on average $15 \%$ to $30 \%$ higher than conventional one (APII, 2016). Organic dates exports occupy the second position with more than 9,000 tons exported during 2018 (CTAB, 2019).

However, the targets of organic farming in Tunisia are far from being achieved, especially with regard to cereals and vegetables (Maamer and Amara, 2014). This explains, in part, the very limited organic food consumption in Tunisia. Indeed, the share of organic products in the food consumption still does not represent $1 \%$ (Rached et al., 2012).

The lack of availability of organic food near consumers, the lack of outlets that is limited to a few weekly market or very small corners in 
Figure 1 - Annual evolution of organic production areas in Tunisia and the number of associated operators.

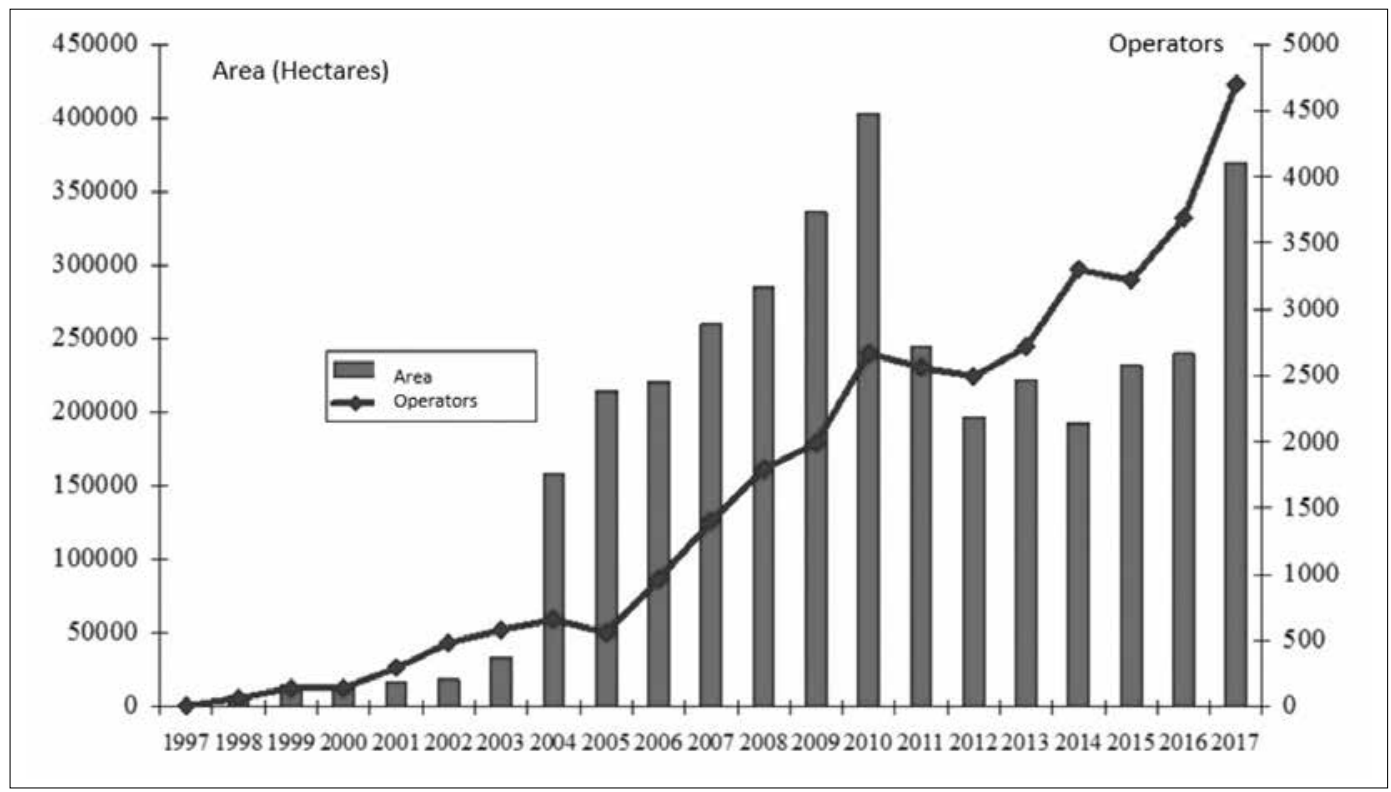

Source: CTAB, 2019.

supermarkets does not improve the situation (Callieris et al., 2016). Exorbitant costs of certification, prices that often exceed the tripe of conventional products and the low willingness to buy of the Tunisian consumer are also part of the problem of commercialization of organic products in Tunisia (Sgaravizzi, 2009). In addition, since the 2011 Tunisian revolution, the inflation rate drastically increased from around $3.5 \%$ to more than $7.5 \%$ in 2018 , which has affected the purchase power of the consumers. The high prices of organic products in the local market are not only due to the high production costs but also the high demand in the export markets and its lucrative prices. In addition, the continuous devaluation of the Tunisia Dinar (TND) during the last eight years (in June 2011, 1 USD $=1.37$ TND; in June 20191 USD = 2.9 TND) worsened the situation by making exported Tunisian agri-food products cheaper in the exports markets, boosting the foreign demand and also allowing the exporting companies to increase their prices and margins, which also explains the limited availability and high prices of domestic organic products on the market. In addition, as mentioned by Callieris et al. (2016), logistics is still difficult because producers are scattered and the wholesale stage is virtually inexistent.

\section{Data collection and methodology}

\subsection{Data collection}

The research was conducted in Tunis City and its suburbs. The choice of Tunis City is justified by the fact that it includes almost two-thirds of Tunisian population and it has the highest number of retail shops selling organic products. It also comprises an important part of the economic activity of the country and where we can find large socio-economic diversity.

Personal face-to-face consumers' interviews were undertaken. A random and quota sampling was applied following the national statistical distribution of individuals using age and gender as clusters. Respondents were approached while they were shopping in supermarkets. All respondents are adults (more than 20 years old). A total of 250 persons were interviewed. The sampling is characterized by balanced rates between the number of women and men respectively with proportions of $49 \%$ and $51 \%$ respectively (very 
close figures to official statistics). According to the age variable, $28 \%$ of respondents are aged between 20 and 30 years and $32 \%$ are made by those aged between 31 and 40 years. Only 18\% of consumers belong to the age stratum 41-50 years and $22 \%$ are over 50 years old (Table 1 ).

The questionnaire included different sections. In the first one, respondents were asked about their knowledge of organic food (acquired awareness and information resources). In the second section, information about organic products consumption (purchased products, purchasing frequency, shopping places, no consumption reasons and willingness to buy) was collected. The third section focused on respondents' perception of various aspects of organic products (price, quality, taste, health and environment effects, labeling, certification, developments, etc.). The last section included descriptive and socio-demographic information about consumers (age, gender, education, household income, family size, etc.).

\subsection{Methodology}

A three-step approach was followed to analyze the collected data. In the first step, descriptive analyses were applied to assess Tunisian consumer behavior towards organic food products. In the second step, data were analyzed using factor and cluster analysis to describe consumer's perceptions. Finally, consumers' segments/clusters external characterization was applied using socio-demographic and lifestyles variables. Chisquare tests were applied to check if the clusters identified were significantly different based on these variables. The analyses were carried out using SPSS (Statistical Package for Social Science) software version 18.0.

\section{Factor Analysis}

Factor Analysis is generally used to identify the structure of a set of variables as well as to provide a process for data reduction (Kennedy et al., 2005; Kennedy et al., 2008; Hair et al., 2010). In this case, component factor analysis also known as principal component analysis was applied to determine the dimensions of respondents' perception towards organic products attrib-
Table 1 - Sample socio-demographic characteristics.

\begin{tabular}{|c|c|}
\hline Characteristic & $\%$ \\
\hline \multicolumn{2}{|l|}{ Gender } \\
\hline Male & 51 \\
\hline Female & 49 \\
\hline \multicolumn{2}{|l|}{ Age (years) } \\
\hline $20-30$ & 28 \\
\hline $31-40$ & 32 \\
\hline $41-50$ & 18 \\
\hline$>50$ & 22 \\
\hline \multicolumn{2}{|l|}{ Family size } \\
\hline 1 & 1 \\
\hline 2 & 9 \\
\hline 3 & 15 \\
\hline 4 & 32 \\
\hline 5 & 20 \\
\hline$>5$ & 23 \\
\hline \multicolumn{2}{|l|}{ Children in the household } \\
\hline 0 & 37 \\
\hline 1 & 30 \\
\hline 2 & 27 \\
\hline 3 & 5 \\
\hline 4 & 1 \\
\hline \multicolumn{2}{|l|}{ Education } \\
\hline None & 1 \\
\hline Primary & 2 \\
\hline Secondary & 22 \\
\hline University & 75 \\
\hline \multicolumn{2}{|l|}{ Household income (Tunisian Dinar) } \\
\hline$<500$ & 6 \\
\hline $501-800$ & 18 \\
\hline $801-1100$ & 20 \\
\hline $1101-1300$ & 15 \\
\hline $1301-1600$ & 20 \\
\hline $1601-1900$ & 11 \\
\hline$>1900$ & 10 \\
\hline
\end{tabular}

utes. Tunisian consumers' perceptions represented by 16 attributes are examined to understand whether they can be grouped in a smaller number of factors. The advantage of this analysis is the reduction in size of the original data matrix 
and the explanation, at the same time, of a maximum amount of variance.

Varimax rotation and Kaiser Normalization were used to identify patterns of factor loadings that were as diverse as possible so that they could be easily interpreted. In this study, as per standard practice (Kennedy et al., 2008), factor analysis was applied with a predetermined cutoff Eigen value of one (Wright et al., 2004). The Bartlett's Test and its associated probability were computed to determine if the correlation matrix comes from a population in which the variables are noncollinear. Kaiser-Meyer-Olkin (KMO) measures sampling adequacy tests whether partial correlations between variables are small; it should be $>0.5$ for a satisfactory factor model. Finally, Cronbach's alphas were estimated to identify the level of internal consistency and to measure the reliability of the factors. It indicates how well a set of variables measures a single underlying construct; it is high when inter-item correlations are high (Kennedy et al., 2008; Nixon and Saphores, 2006).

\section{Cluster analysis}

It is not uncommon to find cluster analysis used as an adjunct to other techniques such as multidimensional scaling, factor analysis, and discriminant analysis (Punj and Stewart, 1983; Begalli et al., 2009).

Unlike other statistical methods for classification, such as discriminant analysis and automatic interaction detection, Cluster analysis makes no prior assumptions about important differences within a population. It is a purely empirical method of classification and as such is primarily an inductive technique (Gerard, 1957).

In this case, two type of Cluster analysis were used to identify segments of consumers using the five factors coefficients of consumer's perception towards organic products obtained with the factor analysis (Jang et al., 2002; Kennedy et al., 2005).

In the first stage, hierarchical clustering procedures generated a complete set of cluster solutions, ranging from all single-member clusters to the one-cluster solution where all observations are in a single cluster. In doing so, the hierarchical procedure provides an excellent frame- work with which to compare any set of cluster solutions and help in judging how many clusters should be retained (Hair et al., 2010).

In the second stage of the cluster analysis, we used the non-hierarchical classification "K-means cluster analysis". The input for the cluster analysis is the dimension factorial scores assigned to each consumer's perception factor. The algorithm utilized to identify consumers who belong to each group was based on the "Ward" method. The number of groups selected was decided using both a row of alternative classification processes and the comparison of the Euclidean distance matrixes between the centroids (Begalli et al., 2009). This iterative partitioning method outperforms hierarchical methods if a nonrandom starting point is specified (Punj and Stewart, 1983; Valeeva et al., 2005).

\section{Results}

\subsection{Consumers' perception about organic products}

Survey results show that about $60 \%$ of respondents have never purchased any organic food, whereas only $40 \%$ of them have at least tried once organic product. Consumption frequency over the year vary from $16 \%$ of consumers who purchase organic food quite often and $56 \%$ of occasional consumers that do not consume organic products more than one or two times per year. Using chi-square test we found that income level seems to be closely related to purchasing organics. $54 \%$ of respondents having high income levels (more than 1,601 TND per month) are buying organic products.

Organic consumers were asked to list the products they were used to consume. Almost a third $(29 \%)$ of them buy fresh fruits and vegetables; $21 \%$ buy pasta and flour. Dairy products come next with $16 \%$ of consumers.

It is important to mention that according to the respondents, the major reasons for not buying organic products were that they do not know them $(51 \%)$ and they do not find them in the retail outlets and open markets (37\%).

Regarding the level of consumers' knowledge and awareness about organic foods in Tunisia, 
it is important to indicate that only $13 \%$ of the respondents consider that they are well informed about organic products. $24 \%$ declared that they do not know at all what is organic agriculture or an organic product. A close correlation exists between the education level and the degree of knowledge about organically produced food. Even though most of the surveyed respondents were more educated than the average population ( $75 \%$ with high level of education), we can still notice that the more educated the respondents are, the more likely they know organic products. In fact, more than $40 \%$ of respondents with a primary or secondary level of education declared that they do not have any information about organic food whereas only $18 \%$ of high educated people said so. Furthermore, significant shifts in knowledge are pointed within the variation of age categories. More than $20 \%$ of young respondents (in the 20-30 years age bracket) declared to be well informed about organic products against only $9 \%$ of the persons in the $45-55$ years age group.

In spite of the lack of information, Tunisians have positive perception about organic products. In fact, about $70 \%$ of respondents agreed that organically grown products are much safer and healthier than conventional products. They not only view organic foods as healthy, but also more than $75 \%$ of respondents said that they are willing to pay a premium for it. $40 \%$ agreed that they would be willing to pay between $20 \%$ and $50 \%$ more for these products. The intention to buy organic products is influenced by consumers' perceptions, such as organics are safer, healthier, and environmentally friendlier than conventional production.

\subsection{Consumers' segmentation}

Table 2 presents the factor loading scores after Varimax rotation with Kaiser Normalization. A total of 16 variables were used in the initial factor analysis. Fourteen of these variables had factor loadings greater than 0.5 . These 16 variables were grouped in five factors, which explained $61 \%$ of the cumulative variance. Reliability coefficients (Conbach's alpha) varied between 0.51 and 0.92 . All the factors had an Eigen val- ue greater than one. KMO measure of sampling adequacy is 0.73 and the Bartlett's test of sphericity is significant $(\mathrm{p}<0.001)$.

Consumers were rating from 1 (very important) to 5 (not important at all) the importance of the 16 variables concerning organic products.

The five factors obtained summarize the overall perception of organic products by Tunisian consumers. They were named as follows: the "Intrinsic characteristics" factor mainly emphasizes the importance of the natural taste, healthier and superior food quality in the consumer evaluation. The "Certification" factor reflects the association of organic products with several annual checking and rigorous regulations of production. The subsequent factor titled "Extrinsic characteristics" regroups three variables of comparison between organic and conventional products; this factor reflects the opinion of consumers about the better aspect of organic products, their positive environmental impact and their higher price. The fourth factor, named "Special food" includes dietetic and without additives products variables. Finally, the "Labels" factor emphasizes labeling aspects of the organic products.

Subsequently, we proceeded to a segmentation of respondents according to differences in their perception of organic food. We used cluster analysis in two stages: a hierarchical cluster analysis (Ward's method, using the squared Euclidean distance) to define the number of groups, followed by a k-means cluster analysis. The segmentation of respondents was based on the key attributes corresponding to the 5 factors of organic products perception previously obtained (Hair et al., 2010). Those attributes are healthy products (Factor 1), Special regulations (Factor 2), Environment preservation (Factor 3), Dietetic products (Factor 4) and Without GMO (Factor 5). It should be noted that concerning the first factor, it is the second most important attribute that was chosen instead of the first one to avoid strong correlations between it and other factor's attributes. The analysis of the correlation matrix (Table 3) shows that there are no significant correlations between the five chosen attributes, which allows proceeding with the Cluster Analysis. 
Table 2 - Rotated factor loading scores, variance explained and Cronbach's alpha for the five identified perception factors.

\begin{tabular}{|l|c|c|c|c|}
\hline \multicolumn{1}{|c|}{ Variables used to construct factors } & $\begin{array}{c}\text { Factor } \\
\text { loading }\end{array}$ & $\begin{array}{c}\text { Variance } \\
\text { explained (\%) }\end{array}$ & Eigenvalues & $\begin{array}{c}\text { Cronbach's } \\
\alpha\end{array}$ \\
\hline Factor 1. Intrinsic characteristics & & 20.70 & 3.31 & 0.92 \\
\hline Natural taste (V3) & 0.73 & & & \\
Safer products (V7) & 0.87 & & & \\
Better quality product (V9) & 0.68 & & & \\
No use of chemicals (V13) & 0.53 & & & \\
Healthy products (V14) & 0.83 & & & \\
Well conserved nutritious quality (V16) & 0.53 & & & \\
\hline Factor 2. Certification & & 13.29 & & \\
\hline Certificated products (V5) & 0.59 & & & \\
Annual checking (V10) & 0.86 & & & \\
Special regulations (V11) & 0.89 & & & \\
\hline Factor 3. Extrinsic characteristics & & 10.04 & & \\
\hline High price (V1) & -0.54 & & & \\
Environment preservation (V4) & 0.67 & & & \\
Better aspect than conventional products (V12) & 0.67 & & & \\
\hline Factor 4. Special food & & 9.65 & & \\
\hline Dietetic products (V6) & 0.75 & & & \\
Without additives (V8) & 0.47 & & & \\
\hline Factor 5. Labels & & & & \\
\hline GMO free (V2) & 0.81 & & & \\
Specific label (V15) & & & \\
\hline
\end{tabular}

Table 3 - Correlations Matrix between the chosen attributes.

\begin{tabular}{|l|c|c|c|c|c|}
\hline & $V 14$ & $V 11$ & $V 4$ & $V 6$ & $V 2$ \\
\hline V14: Healthy products & 1 & 0.016 & 0.090 & 0.125 & 0.118 \\
\hline V11: Special regulations & & 1 & -0.122 & 0.113 & 0.139 \\
\hline V4: Environment preservation & & & 1 & -0.050 & 0.070 \\
\hline V6: Dietetic products & & & & 1 & 0.099 \\
\hline V2: GMO free & & & & & 1 \\
\hline
\end{tabular}

In the first step, the hierarchical cluster analysis allowed the identification of 4 groups of respondents. The visualization of the Dendrogram and the examination of the agglomeration schedule indicated the optimal stopping point for merging clusters (by a bigger jump in the distance coefficient). Based on this information and the final centers of the 4 obtained clusters, we proceeded to the second step of this approach; the k-means cluster analysis.

In addition to characterize the 4 obtained clusters of respondents, a One-Way ANOVA was applied to determine if differences in mean values of perception attributes exist between groups. Using the Test for Homogeneity of Variances 
Table 4 - Mean values of organic food perception attributes according to clusters of respondents.

\begin{tabular}{|c|c|c|c|c|}
\hline \multirow{3}{*}{ Attributes } & \multicolumn{4}{|c|}{ Clusters } \\
\hline & 1 & 2 & 3 & 4 \\
\hline & $55(29 \%)$ & $49(26 \%)$ & $69(37 \%)$ & $15(8 \%)$ \\
\hline Natural taste (V3) & 1.16 & 1.47 & 1.32 & 1.80 \\
\hline Safer products ${ }^{*}(\mathrm{~V} 7)$ & $1.07^{\mathrm{a}}$ & $1.22^{\mathrm{a}}$ & $1.00^{\mathrm{a}}$ & $1.73^{\mathrm{b}}$ \\
\hline Better quality product* (V9) & $1.15^{\mathrm{a}}$ & $1.41^{\mathrm{a}, \mathrm{c}}$ & $1.09^{\mathrm{a}}$ & $1.60^{\mathrm{b}, \mathrm{c}}$ \\
\hline No use of chemicals* (V13) & $1.20^{\mathrm{a}}$ & $1.22^{\mathrm{a}}$ & $1.07^{\mathrm{a}}$ & $2.20^{\mathrm{b}}$ \\
\hline Healthy products* (V14) & $1.02^{\mathrm{a}}$ & $1.39^{\mathrm{b}}$ & $1.04^{\mathrm{ab}}$ & $1.87^{\mathrm{c}}$ \\
\hline Well conserved nutritious quality ${ }^{*}$ (V16) & $1.25^{\mathrm{a}}$ & $1.35 \mathrm{a}^{\mathrm{b}}$ & $1.10^{\mathrm{a}}$ & $1.73^{\mathrm{b}}$ \\
\hline Certificated products (V5) & 1.87 & 1.55 & 1.14 & 2.07 \\
\hline Annual checking*(V10) & $2.15^{\mathrm{a}}$ & $0.73^{\mathrm{b}}$ & $0.48^{\mathrm{b}}$ & $2.13^{\mathrm{a}}$ \\
\hline Special regulations ${ }^{*}(\mathrm{~V} 11)$ & $2.73^{\mathrm{a}}$ & $0.51^{\mathrm{b}}$ & $0.28^{\mathrm{b}}$ & $2.20^{\mathrm{c}}$ \\
\hline High price $^{*}(\mathrm{~V} 1)$ & $1.27^{\mathrm{a}}$ & $1.27^{\mathrm{a}}$ & $1.10^{\mathrm{a}}$ & $1.80^{\mathrm{b}}$ \\
\hline Environment preservation* (V4) & $1.98^{\mathrm{a}}$ & $1.80^{\mathrm{a}}$ & $2.39^{\mathrm{b}}$ & $2.07^{\mathrm{a}, \mathrm{b}}$ \\
\hline Better aspect than conventional products (V12) & 3.22 & 2.16 & 3.12 & 2.60 \\
\hline Dietetic products*(V6) & $1.80^{\mathrm{a}}$ & $2.71^{\mathrm{b}}$ & $1.07^{\mathrm{c}}$ & $2.13^{\mathrm{a}}$ \\
\hline Without additives* (V8) & $1.15^{\mathrm{a}}$ & $1.35^{\mathrm{a}}$ & $1.19^{\mathrm{a}}$ & $1.80^{\mathrm{b}}$ \\
\hline GMO free ${ }^{*}(\mathrm{~V} 2)$ & $1.09^{\mathrm{a}}$ & $1.10^{\mathrm{a}}$ & $1.22^{\mathrm{a}}$ & $3.47^{\mathrm{b}}$ \\
\hline Specific label (V15) & 1.91 & 1.98 & 1.46 & 2.13 \\
\hline
\end{tabular}

*The mean difference is significant at the .05 level using Welch and post-hoc Dunnett's C tests.

$a, b, c$ Mean values in the same row with different exponents are statistically different at $5 \%$.

(the Levene test), the assumption of equal variances of the 4 groups was rejected for all attributes except for the variables V5 (certificated products) and V15 (products with specific label). For this reason, we used robust tests of equality of means (Welch and Brown-Forsythe) and Post-hoc Dunnett's C test for multiple comparison which do not assume equal variances. The results are summarized in Table 4.

The first cluster is represented by about $29 \%$ of the sample. Low mean values of the organic products intrinsic features factor, and more particularly "healthy products attribute" indicate that the persons in this cluster perceive organic products as natural, healthy, safer and better quality products. However, higher mean values relative to the certification factor reveal respondents lack of trust about special regulations and annual checking. It seems also, that this cluster includes persons who care about the absence of additives and GMO from organic products (Table 4). Respondents of this group find organic products quite expensive, despite of the relatively high family income characterizing this group. In fact, most of the members of this cluster have more than 30 years old and have a higher than average income. They have a high education level and various cultural activities (Table 5).

Cluster 2 represents $26 \%$ of the sample size. Members of this group appreciate particularly the positive effects of organic products on preserving the environment but they do not perceive these products as of particularly better quality or healthier compared to the conventional agrifood products. They neither consider organic products as dietetic. Special regulations and annual checking are important characteristics of organic product according to these consumers, and similarly to the first cluster, they find organic products prices relatively high (Table 4). People in this second cluster are younger than those in the first group (almost $40 \%$ of them are under 30 years old) with lower incomes and the lowest education level (Table 5). 
Table 5 - Socio-economic characterization of the four obtained clusters ${ }^{\mathrm{a}}$.

\begin{tabular}{|l|c|c|c|c|c|}
\hline & Cluster 1 & Cluster 2 & Cluster 3 & Cluster 4 & $X^{2}$ \\
\hline Age $<30$ years old & $\mathbf{2 0 . 0 \%}$ & $38.8 \%$ & $21.7 \%$ & $\mathbf{5 3 . 3 \%}$ & $10.63^{* *}$ \\
\hline Having high education & $90.7 \%$ & $\mathbf{7 5 . 5 \%}$ & $76.8 \%$ & $\mathbf{9 3 . 3 \%}$ & $6.70^{*}$ \\
\hline Willingness to pay a higher price & $83.6 \%$ & $75.5 \%$ & $\mathbf{8 4 . 1 \%}$ & $\mathbf{5 3 . 3 \%}$ & $8.15^{* *}$ \\
\hline Having cultural activities & $\mathbf{8 9 . 1 \%}$ & $81.6 \%$ & $88.4 \%$ & $\mathbf{5 3 . 3 \%}$ & $12.78^{* * *}$ \\
\hline Family income $<1100 \mathrm{TD}$ & $32.7 \%$ & $36.7 \%$ & $\mathbf{3 1 . 9 \%}$ & $\mathbf{7 3 . 3 \%}$ & $9.72^{* *}$ \\
\hline
\end{tabular}

${ }^{a}$ We have only included the statistically significant variables. Other socio-economic variables and those related to organic production purchase and knowledge were tested but were not statistically significant.

$*, * *, * * *$ indicate clusters means difference, measured at the 1\%,5\% and 10\% significance levels respectively.

The third cluster is the largest one. It includes $37 \%$ of respondents. In this cluster we found the lowest mean values for the intrinsic characteristics factor. In fact, like in the first cluster, respondents have a clear perception towards the organically produced food's intrinsic characteristics. They also associate organic products with the certification factor and high prices, similarly to the second cluster. However, it seems that persons in this group have certain confusion between dietetic and organic products. The highest mean value of the environmental attribute indicates that this group is not really aware about organic products production process and its contribution to environmental preservation (Table 4 ). This cluster is composed of almost $80 \%$ of people older than 30 years and having cultural activities. This group of respondents belongs to the highest household income category, which explains their willingness to pay higher prices for organic products.

Finally, the fourth cluster is the smallest one; it includes only $8 \%$ of the respondents. The highest mean values of almost all factors reflect respondent's confusion and misinformation about organic products. Not only they do not perceive them as natural or healthier, but also, they have ambiguity about environment preservation contribution, certification and labeling factors. Unlike the other clusters, this group seems unable to give a consistent appreciation about the price because respondents have very limited and erroneous knowledge about this kind of products. Besides, although this last cluster has the highest percentage of universities graduated persons, they still have the lowest cultural activities and household incomes which explains that more than $50 \%$ of them declared to be unable to pay any premium for organic products (Table 5).

\section{Discussion}

The results showed that there is a gap between consumers' perceptions and their claimed or revealed behavior towards organic food products. Respondents have, generally, positive attitudes towards organic products, while the proportion of consumers who purchase organic food on a regular basis remains quite low (16\%). This gap has already been mentioned and summarized in previous studies by Aertsens et al. (2009), Ghali and Hamdi (2015), Salah et al. (2015) and Callieris et al. (2016). According to Kamoun et al., (2015), some Tunisian consumers prefer organic products for rational reasons, which consist in using food products that are controlled and without chemical additives which are "better" for health. Others are motivated by emotions linked to the aspect of responsible citizen in the society and strengthen their self-esteem through these "citizen" actions. Callieris et al. (2016) in their study about organic food consumers in Tunisia, identified three consumer groups of organic products. Regular consumers $(25 \%$ of sample size), promising consumers $(36 \%)$ and the remaining group (39\%) that represents consumers whose organic consumption remains difficult to consolidate. The first two groups have proven to be the most aware of the benefits derived from the consumption of organic products and are able to contribute to the expansion of the organic market. However, there is a need to introduce 
innovations to produce and market organic products at affordable prices, especially for promising organic consumers (Callieris et al., 2016).

The main purchase and consumption barrier for organic food, as stated in literature, is the relatively high price premium (Padel and Foster, 2005; Hughner et al., 2007; Ghali-Zinoubi and Toukabri, 2019). However, in this study, the main constraints hindering the consumption of organic products were the lack of awareness and lower availability of organic food in the traditional retail outlets. The lack of knowledge and awareness was considered as the main reason of why Tunisian consumers do not buy organic food; respondents indicated that they never considered organic products because they did not know them. A second dimension to the knowledge and awareness puzzle is the possibility that those respondents who do not consider organic products may have a general knowledge about them, but do not have enough detailed information to clearly differentiate organic from conventional products.

Although there is some awareness about organic food benefits by Tunisian respondents, it is still very limited compared to European and North American regions. A review of other studies indicated that this awareness is higher especially in Europe, where the organic market is relatively well developed (Bonti-Ankomah and Yiridoe, 2006; Aertsens et al., 2009; Willer and Lernoud, 2017). North America has the lead of retail sales of organic products with 41.9 billion euros followed by Europe (30.7 billion euros) in 2016 (Willer et al., 2018). Results suggest also that consumers have inconsistent interpretations about what is "organic". Furthermore, there was no significant difference in consumers' understanding of "organic" among organic and non-organic food buyers. Other studies that investigated the level of consumer's awareness about organic foods reported confusion and/or inconsistencies with consumers' understanding of the organic concept (Wolf, 2002; Callieris et al., 2016).

In this study we found that significant differences exist between respondents' segments. Only the smallest group showed confusion and contradiction in the perception of organic prod- ucts. This segment does not associate organic products with the no use of pesticides, the healthier or the safer aspects comparatively to conventional products. Providing extra information about the production and control processes of organic products may help to increase knowledge. Gracia and de Magistris (2007), also, found that better knowledge and information help to improve the attitude towards organic food. It may also increase the willingness to pay a price premium (Barnes et al., 2009; McFadden and Huffman, 2017), this may be very rewarding. However, it is important to note that knowledge and awareness about organic products does not necessarily translate into direct purchase because of barriers that could limit the ability of consumers to transform such knowledge and perceived demand into actual demand (Bahri-Ammari et al., 2015).

In our study, the three other consumers' groups seem to be relatively well informed about basic characteristics of organic products. However, they consider that such products are quite expensive. Between $20 \%$ and $25 \%$ of the three clusters respondents consider price surplus as a barrier to consumption.

Although an important segment of respondents is able to identify organic products based on the certification and strict regulations, in this study Tunisian consumers do not give a lot of importance to labels. However, several studies (Mathios, 1998; Kim et al., 2000; Howard and Allen, 2006; Maaya et al., 2018) have found a positive relationship between consumer purchase decisions and product labeling. In fact, consumers generally perceive organic label as a guarantee that the product is organic. More accurately, organic food labels help transform the credence characteristics of such products into search attributes, thereby allowing the consumer to better evaluate quality before deciding to buy the product (Caswell, 2000). Thus, deceptive or inaccurate labeling can convey the wrong signals to prospective buyers.

According to this research, some of the socio-demographic characteristics like age, household income, education level and cultural involvement of respondents have significant influence on organic food perception and intention 
to purchase. Gracia and de Magistris (2007) have found similar results in their study. Although in this case gender and number of children at home do not have significant influences, Stobbelaar et al. (2007) indicate that women and parents with children are generally more concerned about health issues so more interested by organically produced food. Regarding the significant relationship between age and the perception of organic food, findings are not always consistent. Older respondents seem to be less likely to appreciate the characteristics of organic foods. Younger respondents (20-30 years) in contrast have a more positive attitude. However, there were no differences between age groups with respect to purchase decision and frequency. Results suggest that, in spite of their stronger interest, young consumers do not buy organic foods more frequently than older ones.

In this study, the purchase power (household income) has strong influence on consumer buying decision and plays a significant positive role in explaining organic food purchases and willingness to buy. These results are similar to several empirical studies reported by Bonti-Ankomah and Yiridoe (2006), Gracia and de Magistris (2007), Kamoun et al. (2015), and Ghali-Zinoubi and Toukabri (2019). According to Salah et al. (2015), potential consumers estimate that the price difference between organic and conventional dairy products should not exceed $25 \%$. Other studies did not find a significant relation, especially in Europe (Goldman and Clancy, 1991; Loureiro et al., 2001; Wolf, 2002; Zepeda and Li, 2007; Kesse-Guyot et al., 2013).

\section{Conclusions}

Despite the relatively recent introduction of organic production in Tunisia (in comparison with the European market), respondents' perceptions towards organic food are on average positive. Many consumers believe that organic food is healthy, environmentally friendly, and tastier than conventionally grown products. A small proportion of respondents is very confused about the definition of an organic product. Consumer attitudes are linked to a complex set of ideas, motivations, and experiences. Beliefs and perceptions are highly subjective notions. Although in reality such perceptions may or may not be true, the individual who holds the perception thinks that it is true.

Although consumption of organic products is still very limited and occasional, an important group of potential organic consumers has been identified. To increase involvement within targeted segments and to overcome the barriers hindering organic food consumption such as misinformation and unavailability of organic products, some measures should be taken. There is a need to increase consumers awareness and information about organic products through sensitization campaigns (television, radio, social networks, etc.), information days, trade shows and the organization of organic producers-consumers direct markets, educational programs in schools, etc. Because Tunisian consumers allocate low importance to labels, it is also very important to better advertise and inform these consumers about the existence of a specific logo for the organic products which will facilitate for them the identification of such products and plays as a warranty that the product is a real organic product.

Actors in the organic sector would focus more on promoting action towards organic production and on how to increase involvement and reduce uncertainty in relation to organic food consumption. The availability of government support might be of important help. Currently government support is mainly directed to the products/ companies targeting the export market with the allocation of specific subsidies and incentives. Studies showed that organic food and products are healthier compared to the conventional ones, this implies a healthier population. In this perspective, the Tunisian government should provide incentives (like subsidies or tax reduction) to local organic producers and companies to sell their products locally at a lower/subsidized price, attracting thus more consumers.

Improving availability and easiness to access organic food products through the integration in mainstream sales channels will allow lowering the gap between the willingness to purchase organic products and the actual purchase. Indeed, growth of sales may lead to economies of scale 
that may further reduce production and certification costs. In this way there can be an evolution towards new market equilibrium at a considerable higher level of supply and demand volume. Also, if more consumers adopt buying organic food their behavior may be imitated by others. A better coaching of the operators and the increase of the number of the certification bodies also contribute to reduce the cost of certification which may improve the organic consumption in Tunisia.

As we have already mentioned, efforts to popularize organic products consumption cannot have an impact without an encouraging political framework. It is also important to facilitate organic products differentiation in the markets.

Related to these findings we believe it would be interesting if future research focuses more on a detailed description of the values, attitude, involvement, motivations and barriers of different user segments and shed more light on Tunisian political orientation towards organic production. Assessment of Tunisian consumers' willingness to pay using choice experiment techniques or experimental auction will be very useful for producers and retailers of organic products.

As any research, this study has some limitations. First, sample selection was focusing on consumers in Tunis capital city and its suburbs and does not include other regions and cannot represent the whole Tunisian population. Second it is limited to one country; and potential organic food consumers in different countries with different habits may have distinct pattern of consumption for various reasons. Finally, this study emphasized the segmentation of organic food buyers and non-buyers. Thus, it would be also useful that future studies explore segments of organic food buyers.

\section{References}

Aertsens J., Verbeke W., Mondelaers K., Van Huylenbroeck G., 2009. Personal determinants of organic food consumption: A review. British Food Journal, 111(10): 1140-1167.

APII, 2016. Agence de promotion de l'Industrie et de l'Innovation. Transformation et conditionnement de l'huile d'olive biologique, pp. 52.
Bahri-Ammari N., Sandhir S., Dakhli A., 2015. Perception and motivation to purchase organic products in Mediterranean countries: An empirical study in Tunisian context. Journal of Research in Marketing and Entrepreneurship, 17(1): 67-90.

Barnes A.P., Vergunst P., Topp, K., 2009. Assessing the consumer perception of the term 'organic': A citizens' jury approach. British Food Journal, 111(2): 155-164.

Begalli D., Codurri S., Gaeta D., 2009. Wine and web marketing strategies. The case study of Italian specialty wineries. British Food Journal, 111(6): 598619.

Ben Kheder M., 2002. Country reports, Tunisia. $O p$ tions Méditerranéennes, Série B, 40: 139-146.

Bhaskaran S., Polonsky M., Cary J., Fernandez S., 2006. Environmentally sustainable food production and marketing. British food Journal, 108(8): 677-690.

Bonti-Ankomah S., Yiridoe E., 2006. Organic and conventional food: A literature review of the economics of consumer perceptions and preferences. Final Report. Truro: Organic Agriculture Centre of Canada, Nova Scotia Agricultural College, pp. 59.

Botonaki A., Polymeros K., Tsakiridou E., Mattas K., 2006. The role of food quality certification on consumer's food choices. British Food Journal, 108(2): 77-90.

Callieris R., Brahim S., Roma R., 2016. Different consumer behaviours for organic food in Tunisia. A cluster analysis application. New Medit, 2: 53-62.

Caswell J.A., 2000. Valuing the benefits and costs of improved food safety and nutrition. Australian Journal of Agricultural and Resource Economics, 42(4): 409-424.

Coulibaly O., Nouhoheflina T., Aitchedjia C.C., Cherry A.J., Adegbola P., 2011. Consumers' perception and willingness to pay for organically grown vegetables. International Journal of Vegetable Science, 17(4): 349-362. DOI: 10.1080/19315260.2011.563276.

CTAB, 2009. Centre Technique de l'agriculture biologique. www.ctab.nat.tn.

CTAB, 2019. Centre Technique de l'agriculture biologique. www.ctab.nat.tn.

Davies A., Titterington A.J., Cochrane C., 1995. Who buys organic food? A profile of the purchasers of organic food in Northern Ireland. British Food Journal, 97(10): 17-23.

Dekhili S., Sirieix L., Cohen E., 2011. How consumers choose olive oil: The importance of origin cues. Food Quality and Preference, 22(8): 757-762.

Gerard R.W., 1957. Units and concepts of biology. Science, 125: 429-433. 
Ghali Z., Hamdi R., 2015. The purchase and consumption motivations of an organic product by the Tunisian consumer: An application on the prickly pear seed oil (PPS). Journal of North African Research in Business, Article ID 220428. DOI: 10.5171/2015. 220428.

Ghali-Zinoubi Z., Toukabri M., 2019. The antecedents of the consumer purchase intention: Sensitivity to price and involvement in organic product: Moderating role of product regional identity. Trends in Food Science \& Technology, 90: 175-179.

Giannakas K., 2002. Information asymmetries and consumption decisions in organic food product markets. Canadian Journal of Agricultural Economics, 50: 35-50.

Goldman B.J., Clancy K.L., 1991. A survey of organic produce purchases and related attitudes of food cooperative shoppers. American Journal of Alternative Agriculture, 6(2): 89-96.

Gracia A., de Magistris T., 2007. Organic food product purchase behaviour: A pilot study for urban consumers in the South of Italy. Spanish Journal of Agricultural Research, 5(4): 439-451.

Haghiri M., Hobbs J.E., McNamara M.L., 2009. Assessing consumer preferences for organically grown fresh fruit and vegetables in Eastern New Brunswick. International Food Agribusiness Management Review, 12(4): 81-100.

Hair J.F., Black W.C., Babin B.J., Anderson R.E., 2010. Multivariate Data Analysis. A global perspective (7th ed.). London: Pearson.

Hamzaoui Essoussi L., Zahaf M., 2008. Profiling organic food consumers: Motivation, trust orientation, and purchase behaviour. Journal of International Business and Economics, 8(2): 25-39.

Harper G.C., Makatouni A., 2002. Consumer perception of organic food production and farm animal welfare. British Food Journal, 104(3/4/5): 287-299.

Howard P.H., Allen P., 2006. Beyond organic: Consumer interest in new labeling schemes in the Central Coast of California. International Journal of Consumer Studies, 30(5): 439-451.

Hughner R.S., McDonagh P., Prothero A., Shultz C.J., Stanton J., 2007. Who are organic food consumers? A compilation and review of why people purchase organic food. Journal of Consumer Behaviour, 6: $1-17$.

Hutchins R.K., Greenhalgh L.A., 1995. Organic confusion: Sustaining competitive advantage. Nutrition \& Food Science, 95(6): 11-14.

ITES, 2017. Institut Tunisien des Etudes Stratégiques. Revue stratégique sur la sécurité alimentaire et nutritionnelle en Tunisie. Tunis: ITES, pp. 245.
Jang S.C., Morrison A.M., O'Leary J.T., 2002. Benefit segmentation of Japanese pleasure travelers to the USA and Canada: Selecting target markets based on the profitability and risk of individual market segments. Tourism Management, 23(4): 367-378.

Kamoun R., Ghozzi K., Ben Alaya B., 2015. Le marché des produits bio en Tunisie: Mythe ou réalité pour les enseignes de la grande distribution. Revue Marocaine de Recherche en Management et Marketing, 11: 235-259.

Kennedy J., Jackson V., Cowan C., Blair I., McDowell D., Bolton D., 2005. Consumer food safety knowledge: Segmentation of Irish home food preparers based on food safety knowledge and practice. British Food Journal, 107(7): 441-452.

Kennedy J., Michelle W., Ewen C.T., Maria K.L., 2008. Segmentation of US consumers based on food safety attitudes. British Food Journal, 110(7): 691-705.

Kesse-Guyot E., Peneau S., Mejean C. et al., 2013. Profiles of organic food consumers in a large sample of French adults: Results from the Nutrinet-Santé Cohort Study. PloS one, 8(10): e76998.

Kim S.Y., Nayga R.M., Capps Jr. O., 2000. The effect of new food labeling on nutrient intakes: An endogenous switching regression analysis. Journal of Agricultural and Resource Economics, 25(1): 215-231.

Laroche M., Toffoli R., Kim C., Muller T.E., 1996. The influence of culture in pro-environment knowledge, attitude and behaviors: A Canadian perspective. Advances in Consumer Research, 23: 53-62.

Loureiro M.J., McCluskey J.J., Mittelhammer R.C., 2001. Assessing consumer preferences for organic, eco-labeled, and regular apples. Journal of Agricultural and Resource Economics, 26(2): 404-416.

Maamer S., Amara S., 2014. Tunisia. In: Pugliese P., Bteich M.R., Al-Bitar L. (eds.). Mediterranean organic agriculture. Key features, recent facts, latest figures. Report 2014. Valenzano: CIHEAM Bari-MOAN.

Maaya L., Meulders M., Surmont N., Vandebroek M., 2018. Effect of environmental and altruistic attitudes on willingness-to-pay for organic and fair trade coffee in Flanders. Sustainability, 10(12): 4496. https://doi.org/10.3390/su10124496.

Mathios A.D., 1998. The importance of nutrition labeling and health claim regulation on product choice: An analysis of the cooking oils market. Agricultural and Resource Economics Review, 27: 159-168.

McFadden J.R., Huffman W.E., 2017. Willingness-to-pay for natural, organic, and conventional foods: The effects of information and meaningful labels. Food Policy, 68: 214-232. 
Nasir A.V., Karakaya F., 2014. Consumer segments in organic foods market. Journal of Consumer Marketing, 31(4): 263-277.

Nixon H., Saphores J.D.M., 2006. Financing electronic waste recycling Californian households' willingness to pay advanced recycling fees. Journal of Environmental Management, 84: 547-559.

Padel S., Foster C., 2005. Exploring the gap between attitudes and behavior -understanding why consumers buy or do not buy organic food. British Food Journal, 107(8): 606-625.

Papadopoulos S., Zafeiriou E., Karelakis C., Koutroumanidis T., 2018. Organics or not? Prospects for uptaking organic farming. New Medit, 17(1): 13-22.

Peštek A., Agic E., Cinjarevic M., 2018. Segmentation of organic food buyers: An emergent market perspective. British Food Journal, 120(2): 269289.

Popa M.E., Mitelut A.C., Popa E.E., Stan A., Popa V.L., 2019. Organic foods contribution to nutritional quality and value. Trends in Food Science \& Technology, 84: 15-18.

Punj G., Stewart D.W., 1983. Cluster analysis in marketing research: Review and suggestions for application. Journal of Marketing Research, 20(2): 134-148.

Rached Z., Salmi A., Khaldi R., 2012. Les performances techniques des dattes biologiques et conventionnelles en Tunisie: Cas de la région de Hezoua. New Medit, 11(3): 50-58.

Sahota A., 2014. The global market for organic food and drink. In: Willer H., Lernoud J. (eds.), The world of organic agriculture: Statistics and emerging trends 2014. Frick, Bonn: FiBL, IFOAM, pp. 125-131.

Salah M., Boudiche S., Ameur M., Amara S., Bornaz S., 2015. Etude du comportement du consommateur vis-à-vis du lait biologique et dérivés et développement de la filière lait biologique en Tunisie. Journal of new sciences, Agriculture and Biotechnology, 22(1): 996-1001.

Salah M., Boudiche S., Amara, S., Ameur M., Bornaz S., 2016. Stratégie de développement de la filière lait biologique en Tunisie à travers la chaine de valeur. Journal of new sciences, Agriculture and Biotechnology, IABC (10): 1263-1275.

Sgaravizzi J.J., 2009. Etude de positionnement stratégique de la branche agro-alimentaire biologique. Rapport Final. Ministère de l'industrie, de l'énergie et des PME. Cahier du CEPI, 38.
Stobbelaar D.J., Casimir G., Borghuis J., Marks I., Meijer L., Zebeda S., 2007. Adolescents' attitudes towards organic food: A survey of 15- to 16-year old school children. International Journal of Consumer Studies, 31: 349-356.

Tuson J., Lampkin N., 2004. Evaluation of European organic farming policies - Development of indicators employing the means framework. $1^{\text {st }}$ EISFOM European Seminar, Berlin, Germany, April 26-27.

Valeeva N.I, Meuwissen M., Bergevoet R., Oude Lansink A., Huirne R., 2005. Improving food safety at the dairy farm level: Farmers' and experts' perceptions. Review of Agricultural Economics, 27(4): 574-592.

Wandel M., Bugge A., 1997. Environmental concerns in consumer evaluation of food quality. Food Quality and Preferences, 8(1): 19-26.

Willer H., Diana S., Arnaud M., Solfanelli F., 2018. The European market for organic food. Paper presented at BIOFACH Congress, Messezentrum Nürnberg, Nürnberg, Germany, February 14.

Willer H., Kilcher L. (eds.), 2009. The world of organic agriculture. Statistics and Emerging Trends 2009. Frick, Bonn, Geneva: FiBL, IFOAM, ITC, Geneva. Available at www.organic-world.net.

Willer H., Kilcher L. (eds.), 2010. The world of organic agriculture. Statistics and emerging trends 2010. Frick, Bonn: FiBL, IFOAM.

Willer H., Lernoud J. (eds.), 2017. The world of organic agriculture. Statistics and emerging trends 2017. Frick, Bonn: FiBL, IFOAM.

Willer H., Lernoud J. (eds.), 2019. Organic Agriculture Worldwide: Statistics and Emerging trends. Key results from the FiBL survey on organic agriculture worldwide 2019. Frick, Bonn: FiBL, IFOAM, pp. 35-125.

Wolf M.M., 2002. An analysis of the impact of price on consumer interest in organic grapes and a profile of organic purchasers. Paper presented at the American Agricultural Economics Association Annual Meeting, Long Beach, California, July 28-31.

Wright B., Scott I., Woloschuk W., Brenneis F., 2004. Career choice of new medical students at three Canadian universities: Family medicine versus specialty medicine. Canadian Medical Association Journal, 170(13): 1920-1924.

Zepeda L., Li J., 2007. Characteristics of organic food shoppers. Journal of Agricultural and Applied Economics, 39(1): 17-28. 